\title{
Drugs-Inducing Hepatotoxicity
}

\author{
Mohammed M. Alshehri ${ }^{*}$, Muhammad Wahab Amjad ${ }^{2}$ and Mahmoud M. E. Mudawi ${ }^{3}$ \\ 'Department of Pharmacology and Toxicology, Faculty of Pharmacy, University of Tabuk, Kingdom of \\ Saudi Arabia; M.MansourAlshehri@outlook.sa \\ 2Department of Pharmaceutics, Faculty of Pharmacy, Northern Border University, Kingdom of Saudi Arabia; \\ Mwbamjad@yahoo.com \\ ${ }^{3}$ Department of Pharmacology and Toxicology, Faculty of Pharmacy, Northern Border University, \\ Kingdom of Saudi Arabia; Mmudawi@hotmail.com
}

\begin{abstract}
The liver is the largest solid organ, the largest gland, and one of the most vital organs that functions as a center for the metabolism of nutrients and excretion of waste metabolites. Hepatotoxicity is becoming a leading cause of death worldwide and its prevalence is increasing exponentially, there are several causes behind hepatotoxicity such as administration of acetaminophen that induced hepatotoxicity through the excessive formation of the toxic metabolite $\mathrm{N}$-acetyl-para-benzoquinone imine (NAPQI). Drug-induced liver injury may account for approximately $10 \%$ of all cases of acute hepatitis, $5 \%$ of all hospital admissions, and $50 \%$ of all acute liver failures. Remarkably, more than $75 \%$ of cases of idiosyncratic drug reactions result in liver transplantation or death. This review will help researchers to understand the hepatotoxicity mechanism of common drugs that have a hepatotoxic effect.
\end{abstract}

Keywords: Acetaminophen, Anti-Tuberculosis Drugs, Hepatotoxic Drugs, Hepatotoxicity, Phenytoin

\section{Introduction}

The liver is an essential organ and its vital area supports almost every other organ in the body. The liver is additionally the fundamental organ for the metabolism and elimination of medication and other exogenous products. Simultaneously liver is prone to many diseases like hypersensitivity to food and involves the immune system as well. The bare area of the liver is a site that vulnerable to the passing of infection from the abdominal cavity to thorax ${ }^{1}$. Hepatotoxicity refers to liver dysfunction or liver damage that is associated with an overload of drugs or xenobiotics. The synthetic compounds that cause liver damage are called hepatotoxins of hepatotoxicants. Hepatotoxicants are an exogenous mix of clinical pertinence and may incorporate overdose of certain medications, industrial chemicals, plants, and dietary supplements ${ }^{2}$. Drugs metabolize in the liver through oxidation, reduction, hydration, hydrolysis, condensation, conjugation, or isomerization. Two stages of hepatic drug metabolism convert pharmaceutical into conjugated water-soluble substances via P450 enzymes, which are excreted via urine or bile. Although the liver metabolizes drugs, disruption of these processes can lead to hepatotoxicity. Hepatotoxicity occurs through numerous mechanisms: disassembly of hepatocytes, apoptosis of hepatocytes, and injury to the bile duct, and inhibition of mitochondria and cytolytic T-cell activation ${ }^{3}$. More than a thousand drugs and synthetic compounds have been accounted for the cause of hepatic damage. Medication prompted liver injury may represent around $10 \%$ of all cases of acute hepatitis, $5 \%$ of all emergency clinic confirmations, and half of all acute liver failures. Remarkably, over $75 \%$ of cases of idiosyncratic drug reactions result in liver transplantation or death. Druginduced liver injuries are considered a serious problem

${ }^{*}$ Author for correspondence 
for quite a long time; the hepatotoxicity of certain herbal products has only recently been recognized. There are relatively few investigations accessible on this disturbing part of herbal products items to date; however, the danger can't be disregarded as they may give an indistinguishable range of liver pathologies from manufactured items. A large number of herbal and dietary products are reported to have liver-damaging effects. These products when administered may cause symptoms extending from acute, chronic, cholestatic, fulminant, and acute autoimmunelike hepatitis to acute liver failure, and liver cirrhosis ${ }^{4}$.

Examples of drugs commonly induce liver injury

NSAIDs

Methotrexate

Phenobarbital

Valproate

Antituberculosis

Phenytoin

Statins

Methyldopa

Anabolic-Androgenic Steroids

Ketoconazole

Hydralazine

Ticlopidine

Amiodarone

Tamoxifen

Propylthiouracil

Acetaminophen

Halothane

Disulfiram

\section{Examples of drugs commonly induce liver injury}

\subsection{NSAIDs (Non-steroidal anti- inflammatory drugs)}

There are two types of NSAIDs; the first one is nonselective NSAIDs such as diclofenac, ibuprofen, nimesulide, sulindac; and the second one is selective cyclooxygenase (COX)-2 inhibitors such as celecoxib, are broadly utilized for their anti-inflammatory and painrelieving effects. The NSAIDs relieving the pain and produce the anti-inflammatory activities through the inhibition of COX-2 but in platelets, inhibition of COX-1 prompt to inhibition of thromboxane A2 synthesis. This viably represses inhibits platelet aggregation ${ }^{5}$. The mechanism of hepatotoxicity result from NSAIDs is not clearly understood, it may be due to the acidic moiety present in the non-steroidal anti-inflammatory drugs or reactive adducts of their metabolites which bind to host proteins and result in hepatocellular damage, also there is one study showed that selective COX-2 inhibitors such as celecoxib associated with a lesser risk of hepatotoxicity ${ }^{6}$. Clinically apparent hepatotoxicity due to non-steroidal anti-inflammatory drugs is rarely seen which about one to ten cases per 100000 prescriptions ${ }^{7}$.

\subsection{Methotrexate (MTX)}

MTX is a broadly applied folic acid antagonist. Its efficacy has been proved in a wide range of clinical situations such as inflammatory and autoimmune disorders including ulcerative colitis, rheumatoid arthritis, and psoriasis also it can be used as antineoplastic against leukemia, osteosarcoma, and cancer of head, neck, breast, and lung. MTX may cause hepatotoxicity because it decreases the synthesis of methionine and causes inhibition of S-adenosyl methionine in cerebrospinal fluid. Since S-adenosyl methionine has antioxidant effects, its deficiency in patients taking MTX results in increased Reactive Oxygen Species (ROS). At the same time, MTX may directly increase ROS production'. In a recent systematic review about MTX-induced hepatotoxicity, it is found that the incidence of elevated liver transaminases was $49 \%{ }^{10}$.

\subsection{Valproate (VPA)}

Valproate is a drug mainly used in the treatment of epilepsy and bipolar disorder and also in the prevention of migraines. Its mechanism of action is not fully understood, it may enhance the GABA-ergic function through inhibition of catabolism of GABA, increasing the release of GABA and increasing the density of the GABA-B receptors in the brain ${ }^{11}$. VPA hepatotoxicity is accepted to be intervened through hepatocyte's mitochondrial dysfunction. A few examinations likewise mentioned the significant role of oxidative stress and its consequences in VPA hepatotoxicity. ROS formation, lipid peroxidation, deformity in cellular antioxidant enzymes, and glutathione depletion in an archive in various experimental models of VPA hepatotoxicity ${ }^{12}$. However, $44 \%$ of the patients developing hepatotoxicity due to VPA is reversible by reducing the dose or discontinuation of the drug but there is a non-dose-related disorder characterized by hepatic failure which is less common, frequencies of $\mathrm{I}$ in 5,000 to 1 in $20,000^{13}$. 


\subsection{Phenytoin}

Phenytoin is one of the most important anticonvulsant drug that is very effective in controlling a wide assortment of seizure disorders by blockade of $\mathrm{Na}^{+}$channels and perhaps of presynaptic $\mathrm{Ca}^{++}$channels ${ }^{14}$. It has been suggested that the hepatotoxicity of phenytoin is due to a hypersensitivity reaction which is supported by the fact that the patients also develop rash and fever. However, the cytotoxic and immunologic effects of phenytoin may be due to the arene oxides. These arene oxides are electrophilic which is determined by the activity of cytochrome $\mathrm{P} 450$ enzyme on phenytoin and may acrylate cellular macromolecular such as membrane lipids and DNA, subsequently meddling with cellular functions. When the level of arene oxides exceeds the antioxidant capacity of the exposed individuals the oxidative stress can happen. This occurs when phenytoin is given in high doses which exceed the therapeutic level ${ }^{15}$. The frequency of phenytoin induced hepatotoxicity ranges from one per 1000 to one per 10,000 and probably varies by race and ethnicity ${ }^{16}$.

\subsection{Phenobarbital}

Phenobarbital or 5-ethyl-5-phenylbarbituric acid is a substituted barbituric acid, that exerts its antiepileptic action by facilitating GABA mediated inhibition ${ }^{17}$. Phenobarbital produces hepatic injury as part of a more widespread hypersensitivity reaction. Reactive compounds, the arene oxides, are generated by the cytochrome P450 enzyme system during the metabolism of phenobarbital. Arene oxides bind to cellular molecules and appear to trigger an immune response which will lead to hepatotoxicity. The hepatic injury caused by phenobarbital is accompanied by fever, rash, and eosinophilia ${ }^{18}$. A recent prospective study concluded that $<1 \%$ of patients develop an elevation in serum aminotransferases levels during long-term administration of phenobarbital ${ }^{19}$.

\subsection{Anti-Tuberculosis Drugs}

Rifampicin produces its effect by inhibiting bacterial RNA polymerase, the enzyme liable for DNA transcription ${ }^{20}$. The mechanism of action of pyrazinamide and isoniazid is not fully understood because of its uncommon properties. These drugs are known as antituberculosis and its potentially hepatotoxic drugs. Mechanism of hepatotoxicity: A)
Rifampicin: The significant pathway is deacetylation into diacetyl rifampicin and independently hydrolysis delivers 3-formyl rifampicin. The exact mechanism of rifampicin-induced hepatotoxicityis not known and there is no proof for the hepatotoxic metabolite. B) Pyrazinamide: Is changed over to pyrazinoic acid and further oxidized by xanthine oxidase to 5-hydroxypyrazinoic acid, also the mechanism by which pyrazinamide causes hepatotoxicity is not fully understood. C) Isoniazid: The enzyme responsible for acetylation of isoniazid is hepatic enzyme $\mathrm{N}$-acetyltransferase 2, isoniazid is acetylated into acetyl isoniazid after the hydrolyzed into acetylhydrazine and isonicotinic acid. It is hypothesized that acetylhydrazine is the hepatotoxic metabolite of isoniazid. However, recent research, recommend that hydrazine, and not isoniazid or acetylhydrazine, may responsible for isoniazid induced hepatotoxicity ${ }^{21}$. Overall, hepatotoxicity attributed to antituberculosis drugs has been reported in 5\%-28\% of patients treated with antituberculosis drugs ${ }^{22}$.

\subsection{Statins}

Statins such as simvastatin and atorvastatin are used in the treatment of hypercholesterolemia, act by inhibition of 3-hydroxy-3-methylglutaryl coenzyme A (HMG$\mathrm{CoA}$ ) reductase, the enzyme that converts HMG-CoA into mevalonic acid, which considered as cholesterol precursor $^{23}$. The exact mechanism by which statins induce hepatotoxicity is not fully known. Statins may cause hepatotoxicity by causing mitochondrial dysfunction; after treatment with statins, it causes a huge increase in mitochondrial superoxide which leads to mitochondrial impairment ${ }^{24}$. In a study involving 185 patients treated with statins, at clinical presentation, $57.8 \%$ presented with a hepatocellular pattern, $18.3 \%$ a cholestatic, and $23.2 \%$ a mixed one ${ }^{25}$.

\subsection{Anabolic-Androgenic Steroids (AAS)}

AAS such as stanozolol and nandrolone are synthetic derivatives of the male sex hormone testosterone and it has been mishandled for a long time by both professional and novice competitors to improve muscle mass and physical performance ${ }^{26}$. Hepatotoxicity of AAS might be correlated to individual susceptibility and hereditary factors, and in liver tissue. Oxidative stress could represent a causative factor of liver toxicity because of AAS misuse. 
It has been postulated that androgen receptor activation in hepatic cells may cause an increase in ROS which leads to mitochondrial degeneration of hepatic cells, ultimately advancing to the clinical signs of hepatotoxicity observed with the administration of $17 \alpha$-alkylated steroids ${ }^{27}$. It is reported that $6.5 \%$ of $16-18$-year-old boys used AAS. Therefore, both adult and pediatric clinicians should be familiar with hepatic injury associated with the misuse of $\mathrm{AAS}^{28}$.

\subsection{Methyldopa}

Methyldopa considered as the drug of choice in the treatment of non-complicated pregnancy-induced hypertension. The centrally acting sympatholytic action of methyldopa is responsible for its therapeutic effect in the treatment of hypertension during pregnancy which reduces the sympathetic drive to the heart and peripheral circulation, resulting in lowering cardiac output and decrease peripheral vascular resistance ${ }^{29}$. However, methyldopa may cause hepatic necrosis through immunological reaction and there is some evidence support the immunological mechanism such as the absence of a dose relationship and the absence of toxicity in animals, also clinical study indicated that some patient receiving methyldopa and suffering from hepatitis associated with rash or fever, further suggesting a hypersensitivity reaction ${ }^{30}$. An estimated $5 \%$ of nonpregnant women receiving methyldopa have been reported to have mild hepatic injury ${ }^{31}$.

\subsection{Hydralazine}

Hydralazine acts by interfering with the calcium transport in the vascular smooth muscle which dilates arteriolar smooth muscle and lowers the blood pressure, due to this mechanism of action; hydralazine can be used in various cardiovascular diseases such as severe hypertension, myocardial infarction, congestive heart failure ${ }^{32}$. Hydralazine metabolized in the liver to hydralazine and acetyl-hydrazine which may be involved in hepatic injury and the exposure to microsomal enzyme inducer can worse the risk of developing liver damage ${ }^{33}$. However, some case reports believed that immunological of a lupus-like reaction is the primary mechanism responsible for hepatotoxicity due to hydralazine and we should keep it in mind that only a few cases developed hepatic injury due to hydralazine use ${ }^{34}$.

\subsection{Ketoconazole}

Ketoconazole is a member of imidazole antifungal agents, exert its therapeutic effect by preventing the conversion of lanosterol to ergosterol, and this leads to inhibition of ergosterol synthesis and increase fungal cellular permeability due to decrease the amounts of ergosterol existent in the fungal cell membrane ${ }^{35}$. Recent studies conducted in rat hepatocyte culture observed direct hepatocyte toxicity caused by ketoconazole in a concentration-dependent manner. Many enzymes like Flavin-Containing Mono-Oxygenases (FMOs) biotransform ketoconazole to N-Diacetyl-Ketoconazole (DAK) which has intrinsictoxicity more than ketoconazole. Both ketoconazole and DAK can form a covalent bond with hepatic protein and glutathione depletion which lead to toxicity manifested as cellular leakage of Alanine Transaminase (ALT) or Lactic Dehydrogenase (LDH) in a dose and concentration-dependent manner ${ }^{36}$. A recent meta-analysis of 204 studies showed that an overall incidence of ketoconazole-associated hepatotoxicity is 3.6 $\%$ to $4.2 \%{ }^{37}$.

\subsection{Amiodarone}

Amiodarone considered a class III antiarrhythmic drug. It blocks $\mathrm{K}^{+}$currents that responsible for the repolarization of the myocardium during the third phase of the cardiac action potential, also has a potent noncompetitive $\alpha$-blocker and $\beta$-blocker but has no clinically significant negative inotropic effect ${ }^{38}$. However, histological features of amiodarone-induced liver injury are characterized by Mallory bodies, leukocyte infiltration, steatosis, and ballooning of liver cells similar to alcoholic hepatitis. This histological feature occurs due to both amiodarone and its metabolite $\mathrm{N}$-desethylamiodarone that accumulate in hepatocyte particularly in lysosomes and lead to inhibition of phospholipase both A1 and A2, which decrease the elimination of lysosomal lipids and leads to phospholipidosis, this mechanism can cause steatohepatitis and finally leads to irreversible liver cirrhosis ${ }^{39}$. 4-25\% of the patients treated with amiodarone showed an elevation in liver enzymes like aminotransferase and alkaline phosphatase ${ }^{40}$. 


\subsection{Ticlopidine}

Ticlopidine is an antiplatelet drug that belongs to thienopyridine. It is a prodrug that is metabolized to an active form, which has the ability to blocks the adenosine diphosphate receptor that is involved in GPIIb/IIIa receptor activation that responsible for platelet aggregation $^{41}$. The mechanism by which ticlopidine causes hepatotoxicity has not been fully understood. Whether ticlopidine causes cholestatic injury by inducing molecular modification in basolateral and canalicular transport systems needs further studies. Furthermore, an immune allergic mechanism is suggested by the apparent dose independence, the existence of tissue eosinophilia, lymphocytic of plasma cell infiltration in the periportal area, granulomatous hepatitis, and bile duct injury. On the other hand, the result obtained using ticlopidine induced cholestasis in rats suggests that the adverse effect might be caused immediately by ticlopidine or its metabolites rather than by hypersensitivity ${ }^{42}$. The result of the Canadian Americanticlopidine trial showed that 4.4\% of patients participating in this study developed abnormal liver function tests ${ }^{43}$.

\subsection{Propylthiouracil}

Propylthiouracil is a thioamide derivative commonly used in the treatment of hyperthyroidism. It has two claimed mechanisms of action: (1) it binds to thyroid peroxidase and thereby inhibits the conversion of iodide to iodine, (2) it inhibits type III iodothyronine deiodinase enzyme, that responsible for peripheral conversion of $\mathrm{T} 4$ into the active $\mathrm{T} 3^{44}$. Various mechanisms have been suggested for hepatotoxicity due to propylthiouracil including inhibition of glucosyltransferase, reduced bile acid synthesis, and increased oxygen consumption by hepatocytes. Liver biopsy and postmortem examinations of patients developing hepatotoxicity due to using propylthiouracil have detected different degrees of inflammation and liver necrosis. Histological findings of plasmacytic, eosinophilic, and lymphocytic infiltrated along with variable stages of necrosis. However, the exact mechanism of propylthiouracil responsible for inducing hepatotoxicity is not clear ${ }^{45}$ and the overall incidence of hepatotoxicity induced by any antithyroid medication such as propylthiouracil is less than $0.5 \%{ }^{46}$.

\subsection{Tamoxifen}

Tamoxifen is a nonsteroidal anti estrogen used in the treatment and prevention of all stages of estrogen receptorpositive breast cancer which competitively inhibits estrogen binding to its receptor ${ }^{47}$. The hepatic damage of tamoxifen has been credited to the abnormality of mitochondrial $\beta$-oxidation of fatty acids and the formation of reactive oxygen species. Tamoxifen can affect the mitochondria function by reducing the phosphorylation efficiency compromising the electron transfer along the electron transport chain and affecting the integrity of the mitochondria membrane. These results in mitochondrial dysfunction and lead to an increase in ROS production. Also, the metabolic activation of tamoxifen contributes to the excessive production of ROS. Tamoxifen which is a prodrug is transformed in the liver by cytochrome $\mathrm{P} 450$ enzymes to exert its pharmacological effects and during this process, ROS is produced jointly ${ }^{48}$. However, longterm use of tamoxifen is associated with a 30-40 \% risk of developing nonalcoholic fatty liver disease or nonalcoholic steatohepatitis ${ }^{49}$.

\subsection{Halothane}

Halothane is a general inhalation anesthetic due to its actions on various receptors such as activates GABAA, glycine receptors, and antagonizes the NMDA receptor ${ }^{50}$. However, two mechanisms have been proposed for halothane induced hepatotoxicity. First, the metabolic mechanism, halothane is metabolized by two pathways either oxidative or reductive. The intermediate products of the reductive pathway, especially under hypoxic conditions, are mainly responsible for hepatotoxicity through binding with the fatty and macromolecules in the hepatocytes. Second, is an immunological mechanism, halothane or its metabolites causes hypersensitivity reactions that is evident as a positive provocation test when halothane administered in a small dose to anesthetists who had episodes of fever and jaundice after exposure to halothane and in many cases, Lymphocyte Transformation Test (LTT), and Leukocyte Migration Inhibition Test (LMIT) are seen as positive in comparison with the control group this two can be a piece of important evidence support immunological mechanism ${ }^{51}$. Furthermore, there are two forms of 
halothane-associated hepatitis, first (common) that characterized by moderately increased concentrations of liver transaminases, second (uncommon) with an estimated incidence of up to 1:35000 anesthetics that can lead to fulminant hepatic failure ${ }^{52}$.

\subsection{Acetaminophen}

Acetaminophen considered as one of the most popular analgesic and antipyretic drugs worldwide, it does not possess any anti-inflammatory activity and when applied in recommended doses it does not induce gastrointestinal side effects like NSAIDs, acetaminophen can treat fever and pain through its selectivity for inhibiting cyclooxygenase activities in the brain, but further studies may contribute to deeper knowledge about the exact mechanism of acetaminophen ${ }^{53}$. Acetaminopheninduced hepatotoxicity occurs through the excessive formation of the toxic metabolite N-Acetyl-Para-BenzoQuinone Imine (NAPQI), associated with glutathione depletion, oxidative stress, and mitochondrial dysfunction leading to inhibition of Adenosine Triphosphate (ATP) stores. There are many studies document that the toxic metabolite of acetaminophen NAPQI binds to various proteins, especially mitochondrial proteins. In the setting of glutathione reduction, adherence to mitochondrial proteins is essential because mitochondrial protein binding drain native antioxidant functions and alters the mitochondrial ATP-synthase $\alpha$-subunit, leading to insufficient production of ATP. On other hand, the formation of toxic free radicals, such as peroxynitrite, from the reaction of superoxide and nitric oxide, subsequently forming nitrotyrosine adducts inside the mitochondrial considered as other mechanisms of acetaminopheninduced hepatotoxicity. However, glutathione repletion not only gives surplus cysteine as an energy substrate for the Krebs cycle, but it also plays a major role in scavenging free radical and peroxynitrite $\mathrm{e}^{54}$. Acetaminophen reported causing dose-related hepatocellular necrosis, responsible for nearly about 500 deaths annually in the United States alone, as well as 100,000 calls to united state poison control centers, 50,000 emergency room visits, and 10,000 hospitalizations per year ${ }^{55}$.

\subsection{Disulfiram}

Disulfiram considered as carbamate derivative used in alcohol-dependent patients through inhibition of aldehyde dehydrogenase enzyme, which is responsible

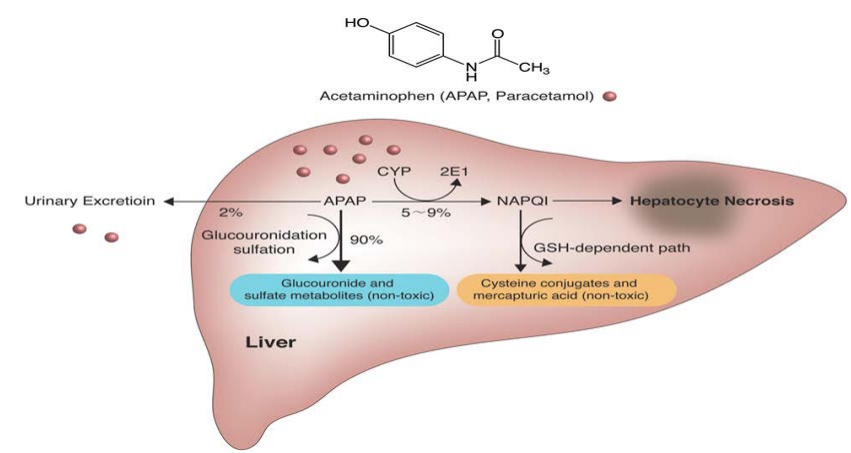

Figure 1. Acetaminophen metabolic pathway (Yoon E. et al, 2016 $)^{56}$. APAP: Acetaminophen, CYP: Cytochrome P450, 2E1: Member of the cytochrome P450, GSH: Glutathione, NAPQI: $\mathrm{N}$-acetyl-pare-benzo-quinone imine ${ }^{56}$.

for the conversion of acetaldehyde to acetate during alcohol metabolism in the liver ${ }^{57}$. The mechanism by which disulfiram produces hepatotoxicity is not fully understood but it may be due to allergic or hypersensitivity reactions and also may be due to the production of toxic metabolites. Disulfiram is reduced by glutathione reductase of erythrocytes to diethylthiocarbamate which is metabolized in the liver by conjugation with glucuronic acid, and one part is metabolized to carbon disulfide (CS2) which can cause peripheral neuropathy and toxic hepatitis ${ }^{58}$. The estimated incidence of acute hepatic injury due to disulfiram treatment is one per 10,000 to 30,000 patients annually ${ }^{59}$.

\subsection{Heparin}

Heparin is a glycosaminoglycan formed of chains of alternating residues of $\mathrm{D}$-glucosamine and uronic acid, with molecular weight ranges from 5,000 to 30,000 Dalton, the anticoagulant effect of heparin intercedes mainly through its interaction with antithrombin-III ${ }^{60}$. Heparin is proposed to cause hepatotoxicity by several mechanisms like changing of hepatocytes membranes, direct toxicity on the hepatocytes, and immune-mediated hypersensitivity reactions. In a study aimed to evaluate the exact mechanism of heparin-induced hepatotoxicity, it is observed notable elevation in High Mobility Group Box 1 Protein (HMGB1) which peaked two days after administration of the last dose of heparin. The study concluded that heparin can prompt transient hepatocyte necrosis followed by activation of the innate immune system $^{61}$. Transaminase elevations were greater than 3 
times the upper limit of normal have been notified to occur in $5 \%$ of patients receiving unfractionated heparin and in $4.3 \%$ to $13 \%$ of patients receiving low molecular weight heparins such as enoxaparin ${ }^{62}$.

\section{Conclusion}

There are large numbers of hepatotoxic drugs that can lead to irreversible hepatic damage and should be cautiously administered especially when given at high doses or used for a long period. However, understanding the exact mechanism by which these drugs cause hepatotoxicity can help the researcher to develop new drugs with less risk of developing a hepatic injury.

\section{Conflict of Interest}

None to declare

\section{References}

1. Gulati K, Reshi MR, Rai N, Ray A. Hepatotoxicity: Its mechanisms, experimental evaluation, and protective strategies. American Journal of Pharmacology. 2018; 1(1):1004.

2. Singh A, Bhat TK, Sharma OP. (2011). Clinical biochemistry of hepatotoxicity. J Clin Toxicol. 2011; 4(0001):1-9.

3. Thompson M, Jaiswal Y, Wang I, Williams L. Hepatotoxicity: Treatment, causes and applications of medicinal plants as therapeutic agents. The Journal of Phytopharmacology. 2017; 6(3):186-193.

4. Stickel F, Patsenker E, Schuppan D. Herbal hepatotoxicity. Journal of hepatology. 2005; 43(5):901. https://doi. org/10.1016/j.jhep.2005.08.002 PMid:16171893

5. Jahnavi K, Reddy PP, Vasudha B, Narender B. Non-steroidal anti-inflammatory drugs: an overview. Journal of Drug Delivery and Therapeutics. 2019; 9(1-s):442-448. https:// doi.org/10.22270/jddt.v9i1-s.2287

6. Sriuttha P, Sirichanchuen B, Permsuwan U. Hepatotoxicity of nonsteroidal anti-inflammatory drugs: a systematic review of randomized controlled trials. International Journal of Hepatology. 2018. https://doi.org/10.1155/2018/5253623 PMid:29568654 PMCid:PMC5820561

7. Liver Tox: Clinical and Research Information on DrugInduced Liver Injury. Bethesda (MD): National Institute of Diabetes and Digestive and Kidney Diseases; 2012.

8. Mahmoud NM. Ppar- $\gamma$ dependent protective effect of pioglitazone against methotrexate-induced hepatotoxicity in rats. Al-AzharAssiut Medical Journal. 2015; 13(2).
9. Kumari S, Kumari S, Sharma AK, Kaur I. Methotrexate induced hepatotoxicity and its management. Inter J Sci Res. 2016; 5:1477-81.

10. García DS, Saturansky EI, Poncino D, Martínez-Artola Y, Rosenberg S, Abritta G, Cravero A. Hepatic toxicity by methotrexate with weekly single doses associated with folic acid in rheumatoid and psoriatic arthritis. What is its real frequency? Annals of Hepatology. 2019; 18(5):765-769. https://doi.org/10.1016/j.aohep.2019.01.011 PMid:31105018

11. Ayano G. Bipolar disorders and valproate: Pharmacokinetics, pharmacodynamics and therapeutic effects and indications of valproate: review of articles. Bipolar Disord. 2016; 2(109):2472-77. https://doi.org/10.4172/2472-1077.1000109

12. Najafi N, Jamshidzadeh A, Fallahzadeh H, Omidi M, Abdoli N, Najibi A, Niknahad H. Valproic Acid-Induced Hepatotoxicity and the Protective Role of ThiolReductants. Trends in Pharmaceutical Sciences. 2017; 3(2):63-70.

13. Stephens JR, Levy RH. Valproate hepatotoxicity syndrome: hypotheses of pathogenesis. Pharmaceutisch Weekblad. 1992; 14(3):118-21. https://doi.org/10.1007/BF01962700 PMid:1502010

14. Yaari Y, Selzer ME, Pincus JH. Phenytoin: mechanisms of its anticonvulsant action. Annals of Neurology: Official Journal of the American Neurological Association and the Child Neurology Society. 1986; 20(2):171-184. https://doi. org/10.1002/ana.410200202 PMid:2428283

15. Ekaidem IS, Usoh IF, Akpanabiatu MI, Uboh FE, Akpan HD. Urate synthesis and oxidative stress in phenytoin hepatotoxicity: the role of antioxidant vitamins. Pak J Biol Sci. 2014; 17(11):1179-1184. https://doi.org/10.3923/ pjbs.2014.1179.1184 PMid:26027163

16. National Institutes of Health. Livertox: Clinical and research information on drug-induced liver injury; 2017. Available from: Nih. gov https://livertox.nih.gov

17. Satishchandra P, Nagappa $M$. Role of phenobarbitone as an antiepileptic drug in 21st century. Medicine. 2012; 22.

18. Bryant AE, Dreifuss FE. Hepatotoxicity associated with antiepileptic drug therapy. Cns Drugs. 1995; 4(2):99-113. https://doi.org/10.2165/00023210-199504020-00003

19. Raksha MA, Lal V, HimaBindu P, Inayathulla K, ManasaG. Hepatotoxicity Induced by Prolonged Use of Phenobarbital: A Case Report. 区International Journal of Science and Healthcare Research. 2020; 5(2):2455-7587.

20. Tostmann A, Boeree MJ, Aarnoutse RE, De Lange WC, Van Der Ven AJ, Dekhuijzen R. Antituberculosis druginduced hepatotoxicity: concise up-to-date review. Journal of Gastroenterology and Hepatology. 2008; 23(2):192202. https://doi.org/10.1111/j.1440-1746.2007.05207.x PMid:17995946

21. Ramappa V, Aithal GP. Hepatotoxicity related to antituberculosis drugs: mechanisms and management. Journal 
of Clinical and Experimental Hepatology. 2013; 3(1):37-49. https://doi.org/10.1016/j.jceh.2012.12.001 PMid:25755470 PMCid:PMC3940184

22. Ambreen K, Sharma R, Singh KP, Kumar S. Antituberculosis drug-induced hepatotoxicity: a review. International Journal of Advanced Biotechnology and Research. 2014; 5(3):423-37.

23. Stancu C, Sima A. Statins: Mechanism of action and effects. Journal of Cellular and Molecular Medicine. 2001; 5(4):378-87. https://doi.org/10.1111/j.1582-4934.2001. tb00172.x PMid:12067471 PMCid:PMC6740083

24. Golomb BA, Evans MA. Statin adverse effects. American Journal of Cardiovascular Drugs. 2008; 8(6):373-418. https://doi.org/10.2165/0129784-200808060-00004 PMid:19159124 PMCid:PMC2849981

25. Karahalil B, Hare E, Koç G, Uslu İ, Şentürk K, Özkan Y. Hepatotoxicity associated with statins. Archives of Industrial Hygiene and Toxicology. 2017; 68(4):25460. $\quad$ https://doi.org/10.1515/aiht-2017-68-2994 PMid:29337684

26. Bond P, Llewellyn W, Van Mol P. Anabolic androgenic steroidinduced hepatotoxicity. Medical Hypotheses. 2016; 93:150-3. https://doi.org/10.1016/j.mehy.2016.06.004 PMid:27372877

27. Solimini R, Rotolo MC, Mastrobattista L, Mortali C, Minutillo A, Pichini S, Palmi I. .Hepatotoxicity associated with illicit use of anabolic androgenic steroids in doping. Eur Rev Med Pharmacol Sci. 2017; 21(1):7-16.

28. Takyar V, Stolz A. Spectrum of Drug Induced Liver Injury Caused by Anabolic Androgenic Steroids Abuse. Current Hepatology Reports. 2019; 18(4):417-24. https://doi. org/10.1007/s11901-019-00490-0

29. Ramalingappa P, Aradhya HV, Hanumantharaya N, Bolarigowda P. Alpha methyldopa induced hepatotoxicity in pregnancy. International Journal of Reproduction, Contraception, Obstetrics and Gynecology. 2014; 3(3):806. https://doi.org/10.5455/2320-1770.ijrcog20140938

30. Maddrey WC, Boitnott JK. (1975). Severe hepatitis from methyldopa. Gastroenterology. 1975; 68(2):351-360. https://doi.org/10.1016/S0016-5085(75)80018-7

31. KashkooliS, Baraty B, Kalantar J. a-Methyldopa-induced hepatitis during the postpartum period. Case Reports; 2014: bcr2014203712. https://doi.org/10.1136/bcr-2014203712 PMid:24577181 PMCid:PMC3939412

32. Knowles HJ, Tian YM, Mole DR, Harris AL. Novel mechanism of action for hydralazine: induction of hypoxiainducible factor- $1 \alpha$, vascular endothelial growth factor, and angiogenesis by inhibition of prolyl hydroxylases. Circulation Research. 2004; 95(2):162-9. https://doi.org/10.1161/01. RES.0000134924.89412.70 PMid:15192023

33. Amjad W, John G, Gulru S. Hydralazine-Induced AutoimmuneHepatitisPrecipitatedbytheBloodTransfusion.
American Journal of Therapeutics. 2018; 25(4):e514-e516. https://doi.org/10.1097/MJT.0000000000000605 PMid:29045246

34. Sharma M, Foge M, Mascarenhas D. A Suspected Case of Hydralazine-Induced Hepatotoxicity: A Case Report and Review of Literature. The American journal of case reports. 2018; 19:800. https://doi.org/10.12659/AJCR.909279 PMid:29980661 PMCid:PMC6066965

35. Van Tyle JH. Ketoconazole; mechanism of action, spectrum of activity, pharmacokinetics, drug interactions, adverse reactionsand therapeuticuse.Pharmacotherapy: TheJournal of Human Pharmacology and Drug Therapy. 1984; 4(6):34373. https://doi.org/10.1002/j.1875-9114.1984.tb03398.x PMid:6151171

36. Greenblatt HK, Greenblatt DJ. Liver injury associated with ketoconazole: review of the published evidence. The Journal of Clinical Pharmacology. 2014; 54(12):1321-9. https://doi.org/10.1002/jcph.400 PMid:25216238

37. Khoza S, Moyo I, Ncube D. Comparative hepatotoxicity of fluconazole, ketoconazole, itraconazole, terbinafine, and griseofulvin in rats. Journal of Toxicology. 2017. https://doi.org/10.1155/2017/6746989 PMid:28261269 PMCid:PMC5316457

38. January CT, Wann LS, Alpert JS, et al. AHA/ACC/ HRS Guideline for the management of patients with atrial fibrillation: A report of the American College of Cardiology/ American Heart Association Task Force on Practice Guideline and the Heart Rhythm Society. Circulation. 2014; 130:e199-e267.

39. Tsuda T, Tada H, Tanaka Y, Nishida N, Yoshida T, Sawada T, Sasaki M. Amiodarone-induced reversible and irreversible hepatotoxicity: two case reports. Journal of Medical Case Reports. 2018; 12(1):95. https://doi.org/10.1186/s13256018-1629-8 PMid:29653592 PMCid:PMC5899395

40. Pendyala VS. A Case of Amiodarone-induced Hepatitis and Review of the Literature. J Hepatol Gastroint Dis. 2016; 2(120):2.

41. Patrono C. Antiplatelet strategies. European Heart Journal Supplements. 2002; 4(suppl_A):A42-A47. https://doi. org/10.1016/S1520-765X(02)90072-6

42. Tsai MH, Tsai SL, Chen TC, Liaw YF. Ticlopidine-induced cholestatic hepatitis with anti-nuclear antibody in serum. Journal of the Formosan Medical Association. 2000; 99(11):866-869.

43. KraslovaI, Muchova L, Vitek L, Novotny A, Svestka T, Bruha R. Ticlopidine-induced cholestatic inflammatory hepatitis: new insights into pathogenetic mechanisms of drug-related hepatotoxicity. European Journal of Inflammation. 2006; 4(1):55-67. https://doi.org/10.1177/1721727X0600400107

44. Carrion AF, Czul F, Arosemena LR, Selvaggi G, Garcia MT, Tekin A, Ghanta RK. Propylthiouracil-induced acute liver 
failure: role of liver transplantation. International Journal of Endocrinology. 2010. https://doi.org/10.1155/2010/910636 PMid:21234410 PMCid:PMC3014703

45. Akmal A, Kung J. Propylthiouracil, and methimazole, and carbimazole-related hepatotoxicity. Expert opinion on drug safety. 2014; 13(10):1397-406. https://doi.org/10.151 7/14740338.2014.953796 PMid:25156887

46. Gomez-Peralta F, Velasco-Martínez P, Abreu C, Cepeda M, Fernández-Puente M. Hepatotoxicity in hyperthyroid patient after consecutive methimazole and propylthiouracil therapies. Endocrinology, Diabetes and Metabolism Case Reports. 2018; (1). https://doi.org/10.1530/EDM-17-0173 PMid:29340156 PMCid:PMC5763277

47. Jena SK, Suresh S, Sangamwar AT. Modulation of tamoxifeninduced hepatotoxicity by tamoxifen-phospholipid complex. Journal of Pharmacy and Pharmacology. 2015; 67(9):1198-206. https://doi.org/10.1111/jphp.12422 PMid:25904227

48. Zhou WB, Zhang XX, Cai Y, Sun W, Li H. Osthole prevents tamoxifen-induced liver injury in mice. Acta Pharmacologica Sinica. 2019; 40(5):608-19. https://doi.org/10.1038/s41401018-0171-y PMid:30315252 PMCid:PMC6786423

49. Wyffels K, Horsmans Y. Tamoxifen-induced hepatotoxicity caused by drug interaction with direct-acting antiviral agents for hepatitis C. Journal of Oncology Pharmacy Practice. 2019; 25(8):2038-2040. https://doi. org/10.1177/1078155218819742 PMid:30563414

50. Black GW. A review of the pharmacology of halothane. British Journal of Anaesthesia. 1965; 37(9):688-705. https:// doi.org/10.1093/bja/37.9.688 PMid:5320091

51. Rosenak D, Halevy A, Orda R. Halothane and liver damage. Postgraduate medical journal. 1989; 65(761):129. https://doi.org/10.1136/pgmj.65.761.129 PMid:2682584 PMCid:PMC2429259

52. Elliott RH, Strunin L. Hepatotoxicity of volatile anaesthetics. British Journal of Anaesthesia. 1993; 70(3):339-48. https:// doi.org/10.1093/bja/70.3.339 PMid:8471380

53. Jóźwiak-Bebenista M, Nowak JZ. Paracetamol: mechanism of action, applications and safety concern. Actapoloniae pharmaceutica. 2014; 71(1):11-23.

54. Yoon E, Babar A, Choudhary M, Kutner M, Pyrsopoulos N. Acetaminophen-induced hepatotoxicity: A comprehensive update. Journal of Clinical and Translational Hepatology. 2016; 4(2):131. https://doi.org/10.14218/JCTH.2015.00052

55. Lee WM. Acetaminophen (APAP) hepatotoxicity-isn't it time for APAP to go away? Journal of Hepatology. 2017; 67(6):1324-31. https://doi.org/10.1016/j.jhep.2017.07.005 PMid:28734939 PMCid:PMC5696016

56. Yoon E, Babar A, Choudhary M, Kutner M, Pyrsopoulos N. Acetaminophen-induced hepatotoxicity: a comprehensive update. Journal of Clinical and Translational Hepatology. 2016; 4(2):131. https://doi.org/10.14218/JCTH.2015.00052

57. Mutschler J, Grosshans M, Soyka M, Rösner S. Current findings and mechanisms of action of disulfiram in the treatment of alcohol dependence. Pharmacopsychiatry. 2016; 49(04):137-41. https://doi.org/10.1055/s-0042-103592 PMid:26987743

58. Forns X, Caballeria J, Bruguera M, Salmerón JM, Vilella A, Mas A, Rodés J. Disulfiram-induced hepatitis. Report of four cases and review of the literature. Journal of Hepatology. 1994; 21(5):853-7. https://doi.org/10.1016/ S0168-8278(94)80249-1

59. National Institutes of Health. Livertox: Clinical and research information on drug-induced liver injury; 2017. Available from; Nih. gov https://livertox. nih. gov

60. Hirsh J, Warkentin TE, Dalen JE, Deykin D, Poller L. Heparin: mechanism of action, pharmacokinetics, dosing considerations, monitoring, efficacy, and safety. Chest. 1995; 108(4):258S-5S. https://doi.org/10.1378/chest.108.4_ Supplement.258S PMid:7555181

61. Bosco M, Kish T. (2019). Hepatotoxicity With Elevated BilirubinSecondary to ProphylacticDoses of Unfractionated Heparin: A Case Report and Review of Heparin-Induced Hepatotoxicity. Journal of Pharmacy Technology. 2019; 35(1):36-40. https://doi.org/10.1177/8755122518803363 PMCid:PMC6313267

62. Arora N, Goldhaber SZ. Anticoagulants and transaminase elevation. Circulation. 2006; 113(15):e698-e702. https:// doi.org/10.1161/CIRCULATIONAHA.105.603100 PMid:16618822 